\title{
First months of employment and new onset of rhinitis in adolescents
}

\author{
E. Riu*, H. Dressel*,\#, D. Windstetter*, , G. Weinmayr", S. Weiland" , C. Vogelberg ${ }^{+}$, \\ W. Leupold ${ }^{+}$, E. von Mutius ${ }^{\star}$, D. Nowak* and K. Radon*
}

ABSTRACT: The aim of the present study was to investigate the incidence of rhinitis in adolescents, taking into account the duration and type of employment in holiday and vocational jobs, and to study latency until development of symptoms.

Participants of the International Study of Asthma and Allergies in Childhood (ISAAC)-II study in Munich and Dresden (Germany), who were enrolled in 1995, were re-contacted by a postal questionnaire in 2002 (aged 16-18 yrs). The questionnaire focused on allergic rhinitis, type and duration of all jobs, and potential confounders. All jobs held for $\geqslant 8 \mathrm{~h} \cdot$ week $^{-1}$ and $\geqslant 1$ month were coded and occupational exposure was assigned by a job-exposure matrix.

Out of the 3,785 participants, 964 reported an employment history. The median (25th-75th percentile) duration of employment was 10 (1-16) months. After adjusting for potential confounders, those working in high-risk occupations (odds ratio (OR) 1.4, 95\% confidence interval (CI) 1.0-2.1) had an increased risk for new onset of rhinitis, especially those exposed to low molecular weight agents (OR 1.8, 95\% $\mathrm{Cl}$ 1.1-2.8). The incidence of rhinitis was highest among those currently employed in a high-risk job for $<10$ months.

Teenagers who start working in high-risk occupations have a higher incidence of rhinitis compared with those not working. This increased risk might occur early on during employment.

KEYWORDS: Adolescence, cohort, Europe, occupational epidemiology, rhinitis

W ork-related rhinitis and asthma are leading causes of occupational diseases in industrialised countries. In recent years, international studies have assessed the prevalence of atopic diseases in childhood (International Study of Allergy and Allergies in Childhood (ISAAC) phase I and II) [1] and in adults (European Community Respiratory Health Study (ECRHS)) [2]. These studies showed a high prevalence of allergic diseases worldwide, and are the basis for current studies on the aetiology and frequency of asthma and allergies. Most epidemiological studies on occupational allergies are cross-sectional [3]. However, cross-sectional studies about occupational diseases in adult populations are thought to be highly affected by the healthy-worker effect [4], and thus underestimate the problem. There are only a few longitudinal studies reporting the incidence of allergic rhinitis, occupational asthma and other allergies. To date, results from general population studies were based on surveillance schemes and national disease registers. High-risk workforce cohort studies comprise a few recently published studies among apprentices [5-8] and newly hired workers [9], designed to reduce the selection biases in those cohorts. Both showed high incidences of work-related rhinitis and asthma, with very short latency periods, especially for rhinitis. For example, HeLlgREN et al. [10] described an incidence rate of noninfectious rhinitis related to an occupational exposure of 13.5 per 1,000 person-yrs in a random population. RODIER et al. [5] studied 387 animal-health apprentices' starting exposure, and found incidences of occupational rhinoconjunctivitis in $24 \%$, with a tendency of early development of these symptoms.

To the current authors' knowledge, there are no prospective studies from the general population starting in childhood and studying adolescents who are at the start of their working life, and who are thus newly exposed to substances that might be responsible for the disease. This population of teenagers still does not suffer from "healthyworker survivor effect", and allows a much better estimate of latency, incidence and natural history of work-related rhinitis.

The aim of the present study was to investigate the incidence of rhinitis attributable to occupational exposure in German adolescents, as well as
AFFILIATIONS

*Institute for Occupational and Environmental Medicine, and 'Dr. von Haunersches Children's Hospital, Munich,

\#Dept of Epidemiology UIm, and +University Children's Hospital Dresden, Germany.

\section{CORRESPONDENCE}

K. Radon

Unit for Occupational and

Environmental Epidemiology and Net Teaching

Institute for Occupational and

Environmental Medicine

Ludwig-Maximilians-University

Munich

Ziemssenstr. 1

D-80336 Munich

Germany

Fax: 498951604954

E-mail: Katja.Radon@

med.uni-muenchen.de

Received:

November 162006

Accepted after revision:

May 122007

\section{SUPPORT STATEMENT}

The study has been supported by the German Ministry for Economy and Labour. E. Riu has been supported by a grant of the European Respiratory Society. Parts of this manuscript have been used for the medical thesis of E. Riu.

STATEMENT OF INTEREST None declared. 
to determine latency from first contact with an allergen/ irritant to the development of symptoms in this group at the beginning of their working life. In this way the role of a lifetime history of holiday and other pre-vocational occupations and professional training on the job on respiratory health could be assessed.

\section{METHODS}

\section{Study population and follow-up questionnaire}

The study population consisted of the participants of the ISAAC II enrolled in Munich and Dresden (Germany) during 1995 and 1996 (aged 9-11 yrs). Details of the study have been described elsewhere [11]. Briefly, information on atopy and respiratory symptoms, as well as potential risk factors, was assessed by parental questionnaire and clinical measurements were performed in parts of the population (skin-prick test, specific and total immunoglobulin E, spirometry and bronchial hyperresponsiveness to $\mathrm{NaCl}$ ).

For the follow-up study, all subjects were traced 7 yrs after baseline, and 4,893 (76.5\%) could be found using population registries from each community (table 1). In 2002, a questionnaire was mailed to these participants (aged 16-18 yrs), and $3,785(77 \%$ of the contacted teenagers) took part in the study (table 1).

The questionnaire included validated items on respiratory symptoms, work-related respiratory symptoms, socio-demographic characteristics and family history of asthma and allergies. Subjects were also asked about their occupational history, including jobs held during holidays and the professions that they were training for, as well as duration of employment in these jobs. In order to only include potentially relevant exposures, only jobs held for $\geqslant 1$ month and $\geqslant 8 \mathrm{~h} \cdot$ week $^{-1}$ were included [12].

The questions of the follow-up questionnaire were mainly obtained from ISAAC [1] and ECRHS [2]. The data were entered into a database, using double entry to minimise errors.

\section{Job-exposure matrix}

The jobs given by the participants were double-coded by two trained coders according to the International Standard Classification of Occupations-88 code [13], and an individual expert re-evaluation step was carried out. Exposure to agents with potential asthma risk was evaluated using an asthmaspecific job-exposure matrix (JEM) [14], which allowed jobs to be classified into three main groups: nonexposed jobs; low-risk jobs (low level of exposure or low-risk agents, i.e. chemicals, irritants, fumes and/or environmental tobacco smoke); and high-risk jobs. The latter were classified into four categories: high molecular weight agents (HMW; agents derived from animals, plants, arthropods or mites, biological enzymes, bioaerosols, latex, flour); low molecular weight agents (LMW; sensitising chemicals, isocyanates, drugs, cleaning products, sensitising wood dusts and metals); mixed environments (agricultural environments, textile industry, metal working fluids); and a very high level of irritants (peak exposures).

\section{Definition of variables considered in the analyses}

The following job categories were considered as predictors: 1 ) never worked $\geqslant 8 \mathrm{~h} \cdot$ week $^{-1}$ for $\geqslant 1$ month (reference); 2) always worked in nonrisk jobs; 3) ever worked in low-risk jobs; and 4) ever worked in high-risk jobs (exposed to HMW, LMW, mixed environments or peak exposures).

\section{TABLE 1 Study population and subjects included in the analyses}

\begin{tabular}{|c|c|c|}
\hline Population & \multicolumn{2}{|c|}{ Participants } \\
\hline Relocated & 1506 & $4893(100)$ \\
\hline Questionnaire response & 2360 & $3785(77)$ \\
\hline No German nationality & $279(7.4)$ & $3506(92.7)$ \\
\hline Ever held a job for $\leqslant 8 \mathrm{~h} \cdot$ week $^{-1}$ or $<1$ month or missing information on intensity/job & $1137(32.6)$ & \\
\hline Ever held a job for $>8 \mathrm{~h} \cdot$ week $^{-1}$ and $\geqslant 1$ month & & $964(27.6)$ \\
\hline Study population & & 2355 \\
\hline \multicolumn{3}{|l|}{ Included in analyses on rhinitis symptoms } \\
\hline Complete information on rhinitis symptoms, no baseline symptoms or rhinitis & 623 & 1732 \\
\hline Complete information on all of the potential confounders & 45 & 1559 \\
\hline Ever held a job for $>8 \mathrm{~h} \cdot$ week $^{-1}$ and $\geqslant 1$ month duration & 941 & 618 \\
\hline
\end{tabular}


Subjects who indicated that they ever worked but did not specify any job held for $\geqslant 8 \mathrm{~h} \cdot$ week $^{-1}$ and a minimum of 1 month $(n=1,137)$ were excluded from the analyses (table 1$)$. Further analyses restricted to subjects who "ever had a job for $>8 \mathrm{~h} \cdot$ week $^{-1}$ and $\geqslant 1$ month duration" had "no risk" as a reference group when studying "risk of occupation" (low risk/ high risk) and "never worked with that exposure group" when studying exposure groups (HMW, LMW, mixed environments).

Finally, single professions at potentially higher risk for the development of respiratory symptoms were analysed. As subjects might have held different jobs, the most recent job was considered relevant for these analyses.

The outcome was new onset of rhinitis during follow-up. The following definitions were used. 1) Rhinitis symptoms: sneezing and runny or blocked nose without a cold or flu in the previous 12 months. 2) Doctor-diagnosed rhinitis: nasal allergies ever diagnosed by a doctor and sneezing and runny or blocked nose without a cold or flu in the previous 12 months. These questions were extracted from the ISAAC questionnaire (questions 2 and 7, respectively).

\section{Statistical methods}

Data were analysed using multiple logistic regression models. The considered confounders were sex, place of residence (Munich or Dresden), socioeconomic status (SES; defined as higher school degree of the parents: $<12$ yrs of schooling versus $>11$ yrs of schooling), smoking (active smoking for $\geqslant 1 \mathrm{yr}$ ) and regular exposure to environmental tobacco smoke (ETS). In addition, asthma and wheeze were considered as potential confounders. However, adjustment did not change the results. Age was not considered as a potential confounder since all subjects were within a limited age range (16-18 yrs). The participants without German nationality $(n=279)$ differed significantly in job choices and course of allergic diseases from the rest of the sample. Due to the fact that the group was too small for stratified analyses, and only four participants lived in Dresden, they had to be excluded from the analyses [11].

To investigate the potential influence of the duration of exposure by exposure group on the incidence of symptoms, both the duration of employment (in months) and the weekly working hours in the current job were divided into quartiles. The first quartile was considered as the reference group.

\section{RESULTS}

\section{Descriptive data}

Overall, $58 \%$ of the participants reported that they ever had a job. Of these, $964(28 \%)$ subjects specified at least one job that was held for $\geqslant 8 \mathrm{~h} \cdot$ week $^{-1}$ and $\geqslant 1$ month duration (table 1 ). Table 2 compares these adolescents to the 1,391 subjects who never had any kind of job.

Working adolescents were less likely to have a higher SES compared with those without a job (46 versus 57\%, respectively), and were more likely to be from Dresden than Munich (54 versus $47 \%$ ), to be smokers (47 versus $26 \%$ ) and to have regular ETS exposure (74 versus 58\%). They were more likely to be in vocational training than attending high school compared with those who did not have a job (40 versus $26 \%$ ).
The incidence of symptoms of rhinitis (sneezing and runny or blocked nose without a cold or flu in the previous 12 months) was higher among those who already had a job compared with nonworking adolescents (37 versus $32 \%$ ), while the baseline prevalence of symptoms of rhinitis differed only slightly between the two groups (26 versus $23 \%$ ).

Subjects reporting symptoms or allergic rhinitis diagnosed by a doctor at baseline were excluded from the following analyses (table 1).

\section{New onset of rhinitis according to occupational exposure}

Table 3 shows the results of the adjusted model for new onset of rhinitis during follow-up.

Adolescents working in high-risk occupations had significantly elevated incidence (odds ratio (OR) 1.49, 95\% confidence interval (CI) 1.07-2.07) of symptoms of rhinitis (model 1).

Additionally, the incidence of symptoms in relation to each exposure group (low risk, HMW, LMW, mixed exposure) was analysed (model 3). Those with exposure to LMW antigens had a significantly higher OR for new onset of rhinitis (OR 1.78, 95\% CI 1.14-2.79). In contrast, no increased ORs were seen for any occupational exposure and doctor-diagnosed rhinitis.

\section{Effect of intensity and length of exposure}

The effect of hours worked per week and latency period (in months of exposure) for new onset of rhinitis symptoms was investigated stratified for subjects employed in high-risk jobs (HMW, LMW mixed exposures or peak exposures), low-risk jobs and jobs not considered exposed based on the JEM. No association between weekly working hours and new onset of symptoms was seen for any of the exposure groups. For those whose last job included exposure to high-risk agents, the incidence was elevated during the first 15 months of employment with the highest incidence between the second to the ninth working month (OR 3.5, 95\% CI 1.3-9.8; fig. 1).

Repeating analyses with subgroups of participants exposed to either HMW agents, LMW agents or mixed exposures (fig. 2), confirmed the results obtained in the high-risk exposure group, for those who worked with HMW agents. However, CIs were wide due to low numbers.

\section{Professions at risk for respiratory symptoms}

In addition, single professions were analysed in comparison to adolescents working in office jobs, which were considered unexposed (table 4). No statistically significant associations were observed. Science technicians had a slightly higher risk for rhinitis symptoms (OR 2.1, 95\% CI 0.9-5.25) and doctordiagnosed rhinitis (OR 2.8, 95\% CI 0.9-8.8). In addition, there was a tendency for an increased OR for symptoms of rhinitis among those involved in nursing, metal workers and construction.

\section{DISCUSSION}

Rhinitis is a very common disease worldwide with an increasing prevalence, especially in developing countries. Rhinitis is not usually a severe disease, but it can strongly affect the social and working life of many patients [15]. There is no standardised definition of occupational rhinitis in the current literature and multiple definitions are currently used 


\section{TABLE 2 Characteristics of the subjects based on job history}

\begin{tabular}{|c|c|c|c|}
\hline & $\mathbf{N}$ & Never held any job & Ever employed ${ }^{\#}$ \\
\hline Subjects & 2355 & $1391(100)$ & $964(100)$ \\
\hline Dresden & 2355 & $648(47)$ & $519(54)$ \\
\hline Munich & & $743(53)$ & $445(46)$ \\
\hline Male & 2355 & $666(48)$ & $453(47)$ \\
\hline Active smoking & 2338 & $365(26)$ & $451(47)$ \\
\hline Actual activity & 2347 & & \\
\hline School & & 997 (72) & $532(55)$ \\
\hline Vocational training & & $362(26)$ & $386(40)$ \\
\hline Other" & & $27(2)$ & $43(5)$ \\
\hline Occupational exposure $^{+}$ & 2355 & & \\
\hline \multicolumn{4}{|l|}{ Baseline symptoms $1995-1996^{\S}$} \\
\hline Rhinitis symptoms & 2283 & $308(23)$ & $243(26)$ \\
\hline Rhinitis symptoms and doctor-diagnosed rhinitis & $1862^{\# \#}$ & $141(13)$ & $117(16)$ \\
\hline Wheezing & 2281 & $132(10)$ & $121(13)$ \\
\hline Doctor-diagnosed asthma & $1830^{\# \#}$ & $87(8)$ & $82(11)$ \\
\hline \multicolumn{4}{|l|}{ Incidence of symptoms ${ }^{f}$} \\
\hline Rhinitis symptoms & 1732 & $330(32)$ & $253(37)$ \\
\hline Rhinitis symptoms and doctor-diagnosed rhinitis & $1604^{\# \#}$ & $91(10)$ & $65(10)$ \\
\hline Wheezing & 2028 & $139(11)$ & $151(19)$ \\
\hline Doctor-diagnosed asthma & $1661^{\# \#}$ & $19(2)$ & $25(4)$ \\
\hline
\end{tabular}

Data are presented as $\mathrm{n}(\%)$, unless otherwise stated. SES: socioeconomic status; ETS: environmental tobacco smoke. ${ }^{\#}$ : $>8 \mathrm{~h} \cdot$ week $^{-1}$ and $\geqslant 1$ month; " : unemployed family manager (e.g. housewife, house husband), looking for a job; ${ }^{+}$: low-risk jobs, i.e. low level of exposure or low-risk agents (chemicals, irritants, fumes and/or ETS); high-risk jobs, i.e. exposure to high molecular weight agents, low molecular weight agents, mixed environments or very high level of irritants; ${ }^{\text {s: }}$ excluding those with missing information; ${ }^{f}$ : excluding those with baseline symptoms; ${ }^{\# \#}$ : excluding subjects without diagnosis but with symptoms at baseline or follow-up.

[16-19]. Different estimates of the prevalence of the disease have been published, possibly due to the use of different diagnostic criteria, a high rate of underdiagnosis, and geographical and occupational variations.

The present results indicate that adolescents at the start of their working life who are involved in high-risk jobs already have a higher risk for new onset of rhinitis (OR 1.49, 95\% CI 1.07-2.07), especially during the first few months of employment (OR 3.5, 95\% CI 1.3-9.8 between the second to the ninth working month) as compared with adolescents not occupationally exposed in holiday jobs or vocational training.

The current study was carried out prospectively in a general population sample, and data on childhood exposure and respiratory diseases, including rhinitis, as well as data from a lifetime job exposure, could be thoroughly investigated. It was possible to trace most of the subjects after 7 yrs and a high response was obtained. Questionnaire instruments used at baseline and follow-up have been validated against clinical measurements $[1,2]$.

The exposure to agents with potential risk for rhinitis was evaluated using an asthma-specific JEM. It has not yet been validated for rhinitis. This matrix is currently used in analyses of the ECRHS and was used in a recently published work by RADON et al. [20]. Causative agents of rhinitis and asthma are very similar [21] and it was repeatedly reported than rhinitis often precedes the development of asthma symptoms in allergic patients [22]. Therefore, the current authors believe the JEM to be an acceptable instrument to evaluate risk exposure for rhinitis.

According to the present results, the first 9 months of employment seem to be crucial for the development of workrelated rhinitis. The decreasing OR for new onset of rhinitis with longer duration of exposure might already indicate a healthy-worker survivor bias [4]. Thus, estimates of prevalence and incidence of rhinitis from cross-sectional studies or from longitudinal studies, not taking lifetime job history into account, may be strongly affected by selection bias and thus underestimate the problem. Repeating the current analyses with subgroups of participants exposed to each of the high-risk groups (HMW agents, LMW agents or mixed environments), partly confirmed the results, with the highest new onset of rhinitis in the first 9 months of employment in the HMW agents group.

Unfortunately, with the present questionnaire, it was not possible to assure the chronological order between occupational 
TABLE 3 Occupational exposure and new onset of rhinitis according to risk of occupation (model 1 and 2) and to exposure group (model 3)

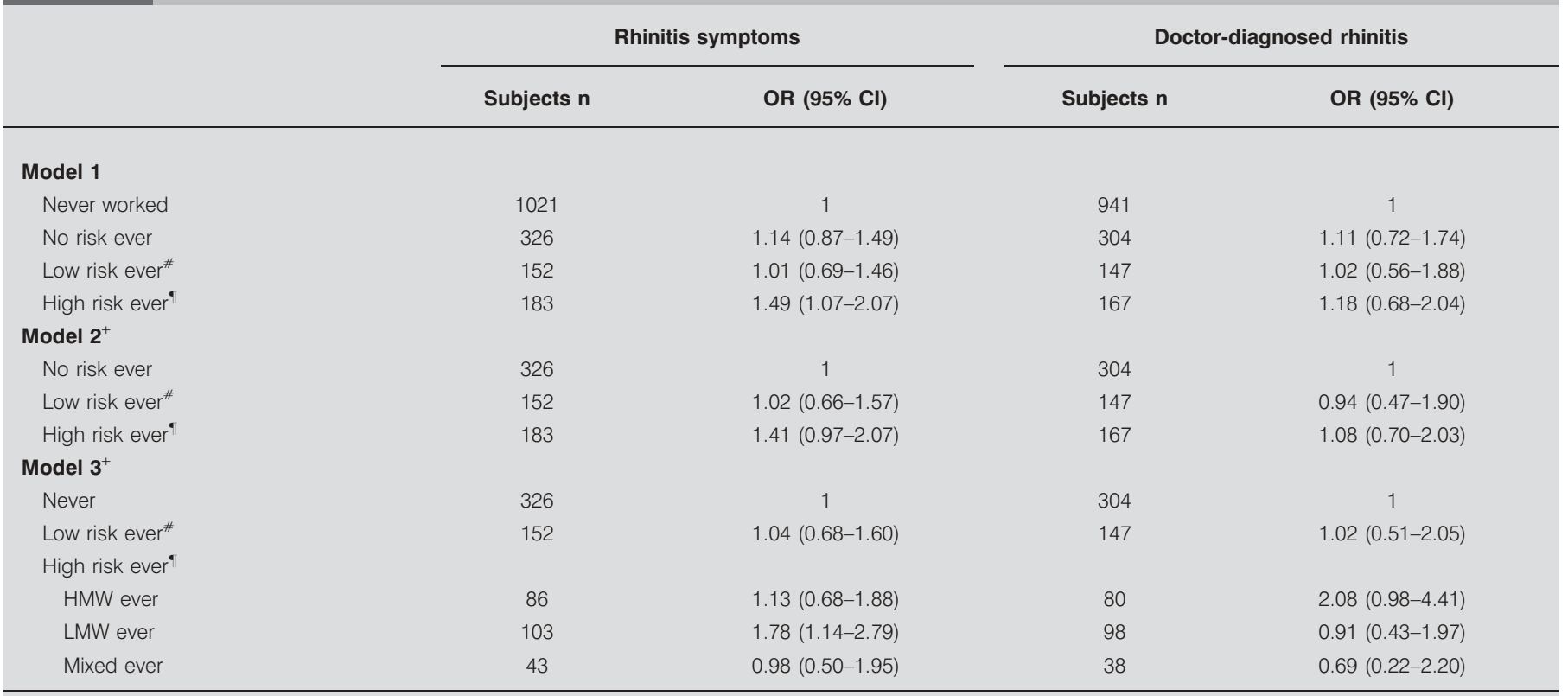

Odds ratios (OR; 95\% confidence interval (Cl)) were adjusted for centre, sex, socioeconomic status, active and passive smoking, and mutually adjusted for the other variables in the model. \#: low-risk jobs, i.e. low level of exposure or low-risk agents (chemicals, irritants, fumes and/or environmental tobacco smoke); ": high-risk jobs, i.e. exposure to high molecular weight agents (HMW), low molecular weight agents (LMW), mixed environments (mixed) or very high level of irritants; ${ }^{+}$: restricted to subjects who ever had a job for $>8 \mathrm{~h} \cdot$ week $^{-1}$ and $\geqslant 1$ month duration.

exposure and incidence of symptoms. Also for this reason, duration of exposure in the most recent job had to be used as proxy of duration of exposure.

A symptom-based definition of rhinitis was used, as well as a definition based on doctors' diagnosis. One might argue that it would also be worthwhile looking at nose and eye symptoms

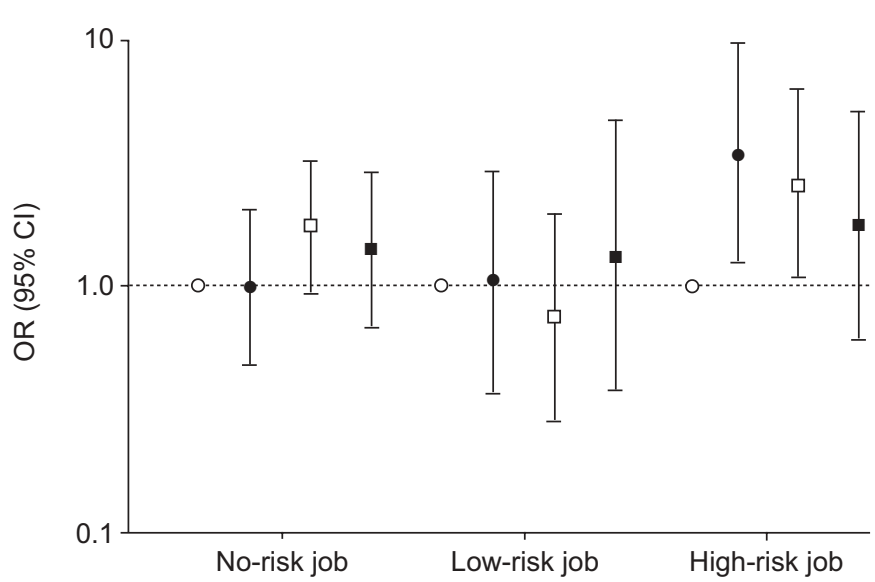

FIGURE 1. Duration of employment in the current or last job and incidence of rhinitis symptoms in no-risk ( $n=336)$, low-risk $(n=143)$ and high-risk jobs $(n=158)$. Odds ratio (OR) with 95\% confidence interval (Cl) was adjusted for centre, sex, weekly working hours, socioeconomic status and active and passive smoking O: 1 month of employment; $\bullet$ : 1-9 months of employment; $\square$ : 10-15 months of employment; $\mathbf{\square}:>15$ months of employment. as symptom-based definition of rhinoconjunctivitis. In $48 \%$ of incident cases of nasal symptoms of rhinitis, new onset of eye symptoms was also reported. All of the 156 new cases of doctor-diagnosed rhinitis reported nose and eye symptoms. Therefore, the following analyses were restricted to the least (rhinitis symptoms) and most (doctor-diagnosed rhinitis) specific definition of rhinitis.

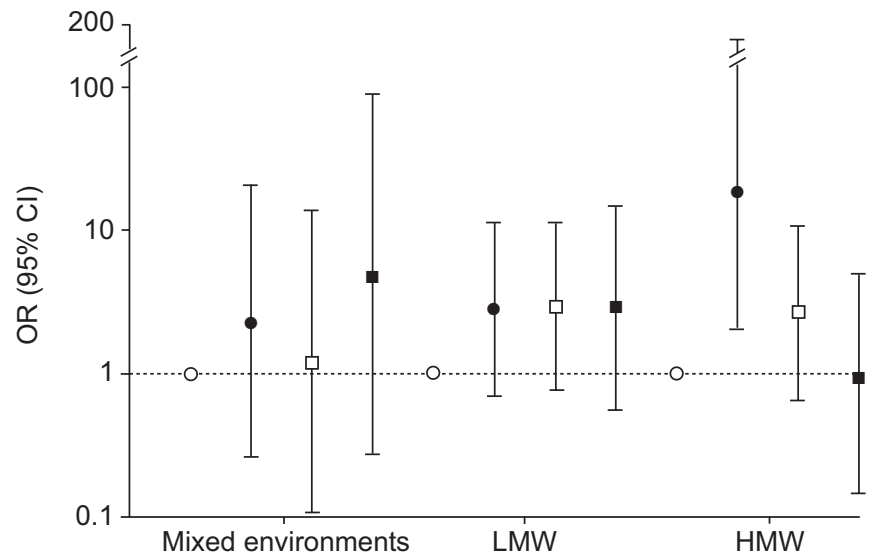

FIGURE 2. Duration of employment in current or last job (high-risk jobs only) and incidence of rhinitis symptoms by type of exposure: mixed environments $(n=34)$; high molecular weight agents (HMW; $n=72)$; and low molecular weight agents ( $L M W ; n=85$ ). Odds ratio $(O R)$ with $95 \%$ confidence interval $(C l)$ was adjusted for centre, sex, weekly working hours, socioeconomic status and active and passive smoking. $\bigcirc: 1$ month of employment; $\bullet$ 1-9 months of employment; $\square:$ 10-15 months of employment; $\mathbf{\square}:>15$ months of employment. 
TABLE 4 Association between current job category and new onset of rhinitis

\begin{tabular}{|c|c|c|c|c|}
\hline Jobs & Subjects $n$ & Rhinitis symptoms & Subjects $n$ & Doctor-diagnosed rhinitis \\
\hline Clerks, shop assistants, childcare workers & 283 & 1 & 253 & 1 \\
\hline Science technicians & 21 & $2.13(0.86-5.25)$ & 22 & $2.84(0.92-8.75)$ \\
\hline Healthcare assistants & 38 & $1.15(0.57-2.33)$ & 35 & $0.72(0.20-2.55)$ \\
\hline Waiters, gastronomy & 88 & $0.91(0.53-1.55)$ & 80 & $0.65(0.25-1.68)$ \\
\hline Construction workers & 29 & $2.22(0.98-5.06)$ & 30 & $1.10(0.28-4.28)$ \\
\hline Metal workers & 29 & $1.76(0.79-3.93)$ & 35 & $0.61(0.13-2.85)$ \\
\hline Carpenters & 8 & & 10 & \\
\hline Electricians & 17 & $0.92(0.31-2.76)$ & 16 & $1.23(0.25-6.07)$ \\
\hline Bakers & 11 & $1.16(0.33-4.13)$ & 9 & \\
\hline
\end{tabular}

Data are presented as odds ratio (95\% confidence interval), which was adjusted for centre, sex, socioeconomic status, and active and passive smoking.

The current authors found that adolescents working in high-risk occupations had an increased risk for rhinitis symptoms, but the same result was not found when looking at doctor-diagnosed rhinitis. This could be due to the small number of cases in this group and thus a lack of statistical power. Little is known about the use of health services in this population of working adolescents. It is possible that adolescents who were already working and mostly from families with lower SES were not visiting their general practitioner for the diagnosis of rhinitis.

It would have been interesting to stratify the current analyses according to asthma. However, only 18 of the participants with new onset of doctor-diagnosed rhinitis reported asthma. Therefore, the number was too low to perform stratified analyses.

In conclusion, the present study indicates a higher risk for rhinitis in occupationally active adolescents compared with those not working. Even exposure in holiday jobs might thus be relevant for the development of rhinitis. Studies including a larger number of subjects are needed to better determine the incidence and course of work-related rhinitis.

\section{REFERENCES}

1 Asher MI, Keil U, Anderson HR, et al. International Study of Asthma and Allergies in Childhood (ISAAC): rationale and methods. Eur Respir J 1995; 8: 483-491.

2 Burney P. Ten years of research on asthma in Europe. The European Community Respiratory Health Survey. Rev Epidemiol Sante Publique 1998; 46: 491-496.

3 El-Zein M, Malo JL, Infante-Rivard C, Gautrin D. Incidence of probable occupational asthma and changes in airway calibre and responsiveness in apprentice welders. Eur Respir J 2003; 22: 513-518.

4 Radon K, Goldberg M, Becklake M. Healthy worker effect in cohort studies on chronic bronchitis. Scand J Work Environ Health 2002; 28: 328-332.

5 Rodier F, Gautrin D, Ghezzo H, Malo JL. Incidence of occupational rhinoconjunctivitis and risk factors in animal-health apprentices. J Allergy Clin Immunol 2003; 112: 1105-1111.

6 Iwatsubo Y, Matrat M, Brochard P, et al. Healthy worker effect and changes in respiratory symptoms and lung function in hairdressing apprentices. Occup Environ Med 2003; 60: 831-840.

7 De Zotti R, Bovenzi M. Prospective study of work related respiratory symptoms in trainee bakers. Occup Environ Med 2000; 57: 58-61.

8 Walusiak J, Hanke W, Gorski P, Palczynski C. Respiratory allergy in apprentice bakers: do occupational allergies follow the allergic march? Allergy 2004; 59: 442-450.

9 Wang XR, Pan LD, Zhang HX, Sun BX, Dai HL, Christiani DC. Lung function, airway reactivity, and atopy in newly hired female cotton textile workers. Arch Environ Health 2003; 58: 6-13.

10 Hellgren J, Lillienberg L, Jarlstedt J, Karlsson G, Toren K. Population-based study of non-infectious rhinitis in relation to occupational exposure, age, sex, and smoking. Am J Ind Med 2002; 42: 23-28.

11 Weiland SK, von Mutius E, Hirsch T, et al. Prevalence of respiratory and atopic disorders among children in the East and West of Germany five years after unification. Eur Respir J 1999; 14: 862-870.

12 Radon K, Riu E, Dressel H, et al. Adolescents' jobs and the course of dermatitis symptoms throughout puberty. Scand J Work Environ Health 2006; 32: 132-137.

13 International Labour Office. International Standard Classification of Occupations (ISCO-88). Geneva, ILO Publications, 1991; pp. 1-457.

14 Kennedy SM, Le Moual N, Choudat D, Kauffmann F. Development of an asthma specific job exposure matrix and its application in the epidemiological study of genetics and environment in asthma (EGEA). Occup Environ Med 2000; 57: 635-641.

15 Bachert C, van Cauwenberge P. The WHO ARIA (allergic rhinitis and its impact on asthma) initiative. Chem Immunol Allergy 2003; 82: 119-126. 
16 Gautrin D, Desrosiers M, Castano R. Occupational rhinitis. Curr Opin Allergy Clin Immunol 2006; 6: 77-84.

17 Slavin RG. Occupational rhinitis. Ann Allergy Asthma Immunol 2003; 90: 2-6.

18 Castano R, Thériault G, Gautrin D. The definition of rhinitis and occupational rhinitis needs to be revisited. Acta Otolaryngol 2006; 126: 1118-1119.

19 Siracusa A, Marabini A, Pace ML. Occupational rhinitis. Monaldi Arch Chest Dis 2002; 57: 127-129.
20 Radon K, Huemmer S, Dressel H, et al. Do respiratory symptoms predict job choices in teenagers? Eur Respir J 2006; 27: 774-778.

21 Hytonen M, Kanerva L, Malmberg H, Martikainen R, Mutanen P, Toikkanen J. The risk of occupational rhinitis. Int Arch Occup Environ Health 1997; 69: 487-490.

22 Umeki S. Allergic cycle: relationships between asthma, allergic rhinitis, and atopic dermatitis. J Asthma 1994; 31: 19-26. 